\title{
Performance-based seismic assessment of vulnerability of dam using time history analysis
}

\author{
Oumnia ELMRABET ${ }^{1 *}$, Hasnae BOUBEL ${ }^{1}$, El Mehdi Echebba ${ }^{1}$, Mohamed ROUGUI ${ }^{1}$ and Ouadia MOUHAT ${ }^{1}$ \\ ${ }^{1}$ University Mohammed V, LGCE High School of Technology- Salé, Rabat, Morocco
}

\begin{abstract}
The current performance-based seismic assessment procedure can be computationally intensive as it requires many time history analyses (THA) each requiring time intensive post-processing of results. Time history analysis is a part of structural analysis and is the calculation of the response of a structure to any earthquake. It is one of the main processes of structural design in regions where earthquakes are prevalent. The objective of this study is to evaluate the seismic performance of embankment dam located on the Oued RHISS in the Province of AL HOCEIMA using the THA method. To monitor structural behavior, the seismic vulnerability of structure is evaluated under real earthquake records with considering the soil-structure-fluide interaction. In this study, a simple assistant program is developed for implementing earthquake analyses of structure with ANSYS, ground acceleration-time history data are used for seismic analysis and dynamic numerical simulations were conducted to study and identify the total response of the soil-structure system.
\end{abstract}

Keywords. Time History Analysis, embankment dam, finite elements method, soil-structure interaction, nonlinear behavior, earthquake, ANSYS.

\section{Introduction}

The prediction of the dynamic behavior of dams under seismic loads is a very important issue in the evaluation of their safety in seismic zones. This essentially requires a rational knowledge of the seismic action acting on all the points of connection of the structure with the foundation soil.

The flexibility of soil modifies the dynamic behavior of the supported structure, which in turn generates interaction forces that disrupt the movement of the ground. This phenomenon, designated by soil-structure interaction [1], is a multidisciplinary field of research that remains active given the complexity of the phenomena concerned. The ongoing researches is aimed at solving a multitude of problems encountered both in practice and in numerical modeling.

Moreover, the problem of the application of seismic loading in soil-structure interaction constitutes another difficulty, considering that the incident seismic waves are physically defined in infinite medium and considered as incident plane waves coming from the focus of the earthquake Located in depth and therefore of vertical incidence. Two methods are used in this context; The methods by substructuring [2], applicable in the case of supposed linear behavior of the foundation soil and the global methods to treat the case where the foundation soil has a non-linear behavior [3]. In the latter case, part of the soil is modeled by finite elements, limited to its base by a horizontal surface where the seismic movement is applied. It is in this context that this article is organized.
First, a finite element 3D modeling [4] of the soilstructure system is presented. This modeling takes into account the effects of the non-linear behavior of the structure and the soil, as well as the effects of the SSI. Next, seismic records are loaded from PEER (Strong Motion Database) and seismic analysis files are produced in ANSYS Parametric Design Language (APDL) [5]. The damping value and the direction of the seismic load are introduced into the system. The modal analysis is performed, and the frequency value of the first vibration mode is recorded. The coefficients $\alpha$ and $\beta$ for the Rayleigh damping are calculated using this value. Then, the time history analysis [6] is executed by applying each acceleration value to the model step by step.

\section{Methods of calculation used}

\subsection{Global method: soil structure interaction}

In the seismic calculation of structures, the excitation is defined by one or more acceleration records often measured at the surface of the ground in the absence of any construction. These records give the accelerograms in free fields. In the presence of a structure, the movements near the foundations may differ from those in the free field. Indeed, the forces at the contact between the structure and its foundation disturb the movement of the ground, and the moment of embedment at the base causes the rotation of the latter. This phenomenon is referred to as "Soil-Structure Interaction" or "SSI". 
We are led to design models in which the ground is represented either by springs [2] or by finite elements or by other types of modeling allowing to reproduce its behavior.

The global method treats the sol-structure interaction problem as a whole: the numerical model is based on the spatial discretization of structure and soil. This method makes it possible to include in principle any nonlinear behavior of the soil or the structure and any heterogeneity present in the soil.

The matrix system resulting from the discretization of the complete problem is written:

$\mathrm{M} \ddot{u}+\mathrm{C} \dot{u}+\mathrm{F} u=\mathrm{Q}(t)$

In equation (1), $u, \dot{u}$ and $\ddot{u}$ are respectively the unknown relative displacements, velocities and accelerations vectors, with respect to the model's base. M is the mass matrix of the soil-structure system, $\mathrm{C}$ the damping matrix and the nonlinear term $\mathrm{F}(u)$ reduces to $\mathrm{K} u$ - where $\mathrm{K}$ is the stiffness matrix of the soil-structure system - in the linear case. $\mathrm{Q}(t)$ is a source term, and is equal to the inertial force $-\mathrm{M} 1 \mathrm{üg}(t)$ induced by the ground seismic acceleration üg.

\subsection{Time history analysis method}

The direct integration of the dynamic motion equation of the Dam agitated from the foundation below applied to a finite element model avoids-although at the expense of increased computational effort the disadvantages of model analysis. Hereby the time history of a vibrating system can be analyzed for finite time steps (step-bystep) more suitably and non-linear soil behavior can be modeled.

Below same numerical methods of direct integration shall be discussed. Explicit and implicit integration methods. In the first case for the solutions of the differential equation, the system is considered at time $t$ for the second type of analysis at time $t+\Delta t[7]$.

\subsubsection{Method of central Differences}

In this explicit method, the unknown displacements $u(t+\Delta t)$ are calculated from the state of equilibrium at time $t$. Velocity and acceleration are found from:

$$
\begin{gathered}
\dot{u}(t)=0.5 \frac{u(t+\Delta t)-u(t-\Delta t)}{\Delta t} \\
u(t)=\frac{u(t-\Delta t)-2 u(t)+u(t+\Delta t)}{(\Delta t)^{2}}
\end{gathered}
$$

\subsubsection{Houbolt's Method}

Equilibrium at time $(t+\Delta t)$ is considered and the displacements $u(t+\Delta t)$ are found in dependence of $u(t), u(t-\Delta t)$ and $u(t-2 \Delta t)$.Velocity and acceleration are given by:

$$
\begin{aligned}
& \dot{u}(t+\Delta t)=\left[\begin{array}{l}
11 u(t+\Delta t)-18 u(t)+9 u(t-\Delta t)- \\
2 u(t-2 \Delta t)
\end{array}\right] / 6 \Delta t \\
& \ddot{u}(t+\Delta t)=\left[\begin{array}{l}
2 u(t+\Delta t)-5 u(t)+4 u(t-\Delta t)- \\
u(t-2 \Delta t)
\end{array}\right] /(\Delta t)^{2}
\end{aligned}
$$

\subsubsection{Method after Wilson}

This method of integration developed by Wilson is based on the assumption that acceleration changes in early during the time interval between $t$ and $t+\theta \Delta t$.

$$
\ddot{u}(t+\Delta t)=\ddot{u}(t)+\frac{\Delta \tau}{\theta \cdot \Delta t}(\ddot{u}(t+\theta \cdot \Delta t)-\ddot{u}(t)) ; 0 \leq \Delta \tau \leq \theta . \Delta \mathrm{t}
$$

For reasons of computational stability $\theta$ must be greater than 1.37 .

\subsubsection{Newmark's Method}

$$
\begin{gathered}
u(t+\Delta t)=u(t)+\dot{u}(t) \Delta t+\left(\begin{array}{l}
(0.5-\beta) \ddot{u}(t)+ \\
\beta \ddot{u}(t+\Delta t)
\end{array}\right) /(\Delta t)^{2} \\
u(t+\Delta t)=u(t)+\left(\begin{array}{l}
(1-\gamma) \ddot{u}(t)+ \\
\gamma \ddot{u}(t+\Delta t)
\end{array}\right) / \Delta \mathrm{t}
\end{gathered}
$$

Stability can be guaranteed if:

$$
\gamma \geq 0.5 \text { and } \beta \geq 0.25 \cdot(0.5+\gamma)^{2}
$$

Dynamic full-time analysis - universally recognized as the one reproducing the best the behavior of a structure under seismic loads - can be successfully applied to large meshes due to the evolution of software performance of finite element calculations, but also of the machines on which they operate. However, it remains difficult to implement since it depends strongly on a coherent seismic input (series of accelerograms) [8], a correct choice of boundary conditions and constitutive laws adapted in the presence of unsaturated soil. The advantage over the replacement force method lies in the explicit consideration of the non-linearity of the materials and consequently the mobilization of the hidden reserves in the behavior coefficient $\mathrm{q}$ present in the calculation of the replacement forces.

\section{Finite element computational model}

The dam studied is located on OUED RHISS in the province of Hoceima, Morocco. With $84,5 \mathrm{~m}$ in height and $430 \mathrm{~m}$ in width.

All civil engineering structures exhibit a certain degree of interaction or coupling with the surrounding environments. The soil-structure coupling is often treated using the finite element method which allows to treat the case of non-linear behavior. 
In this paper, the dynamic analysis of the dam is performed using the finite element computational model for the three-dimensional dam. We note that the damreservoir interaction is considered. The mesh of the dam section is shown in Figure 1. The material properties used in this study are as follow in the table 1 .

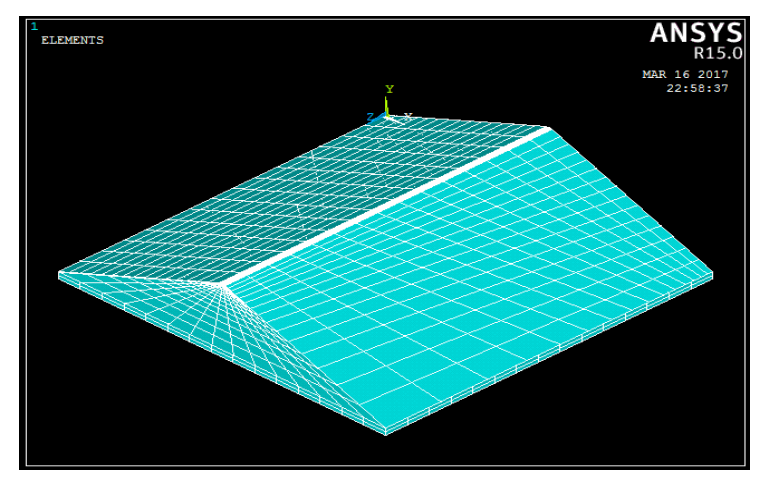

Fig. 1. Mesh of dam.

Table 1. Material properties.

\begin{tabular}{|c|c|c|c|}
\hline Parameters & $\begin{array}{c}\text { Elastic } \\
\text { modulus } \\
(\mathrm{MPa})\end{array}$ & $\begin{array}{c}\text { Poisson's } \\
\text { ratio }\end{array}$ & $\begin{array}{c}\text { Density } \\
\left(\mathrm{t} / \mathrm{m}^{3}\right)\end{array}$ \\
\hline Foundation & 1000 & 0,25 & 2,5 \\
\hline $\begin{array}{c}\text { Upstream } \\
\text { mask }\end{array}$ & 75 & 0,3 & 2,3 \\
\hline
\end{tabular}

\section{Numerical results analysis}

\subsection{Modal analysis}

\subsubsection{Influence of soil-structure interaction on the variation of dam's natural periods and displacements}

The analysis of free vibrations of the dam alone and of the dam-reservoir system is the subject of the first step of this study.

A modal analysis is made to follow the period's variation and displacements of the structure with and without interaction of foundation in order to understand its influence on the dam's response. Table 2 lists the values of the periods obtained for the first five modes of vibration.

Table 2. Modal properties of dam without foundation.

\begin{tabular}{|c|c|c|c|c|c|}
\hline Mode & Frequency & Period & $\mathbf{U}_{\mathbf{X}}$ & $\mathbf{U}_{\mathbf{Y}}$ & $\mathbf{U}_{\mathbf{Z}}$ \\
\hline 1 & 0,39 & 2,57 & $8,70 \mathrm{E}-09$ & $1,19 \mathrm{E}-05$ & $2,56 \mathrm{E}-05$ \\
\hline 2 & 0,42 & 2,38 & $-2,39 \mathrm{E}-09$ & $-1,58 \mathrm{E}-05$ & $-3,19 \mathrm{E}-05$ \\
\hline 3 & 0,44 & 2,27 & $1,26 \mathrm{E}-05$ & $8,44 \mathrm{E}-08$ & $1,91 \mathrm{E}-07$ \\
\hline 4 & 0,45 & 2,23 & $-2,11 \mathrm{E}-05$ & $-4,50 \mathrm{E}-08$ & $-5,73 \mathrm{E}-08$ \\
\hline 5 & 0,48 & 2,09 & $2,53 \mathrm{E}-05$ & $-1,43 \mathrm{E}-07$ & $-3,97 \mathrm{E}-07$ \\
\hline
\end{tabular}

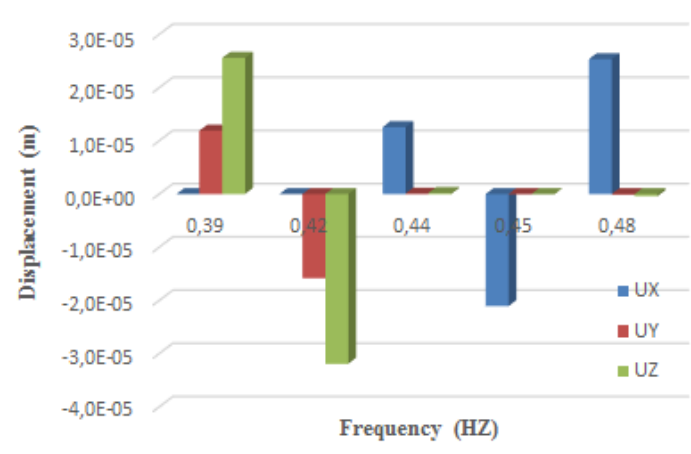

Fig. 2. Variation of displacements.

Table 3. Modal properties of dam with foundation.

\begin{tabular}{|c|c|c|c|c|c|}
\hline Mode & Frequency & Period & $\mathbf{U}_{\mathbf{X}}$ & $\mathbf{U}_{\mathbf{Y}}$ & $\mathbf{U}_{\mathbf{Z}}$ \\
\hline 1 & $8,07 \mathrm{E}-02$ & 12,40 & $1,87 \mathrm{E}-16$ & $-6,68 \mathrm{E}-16$ & $-2,49 \mathrm{E}-06$ \\
\hline 2 & 0,10626 & 9,41 & $-2,31 \mathrm{E}-06$ & $9,29 \mathrm{E}-06$ & $9,10 \mathrm{E}-07$ \\
\hline 3 & 0,13081 & 7,64 & $1,07 \mathrm{E}-06$ & $1,08 \mathrm{E}-05$ & $2,49 \mathrm{E}-06$ \\
\hline 4 & 0,24669 & 4,05 & $-2,59 \mathrm{E}-06$ & $-2,94 \mathrm{E}-06$ & $9,69 \mathrm{E}-07$ \\
\hline 5 & 0,2485 & 4,02 & $3,28 \mathrm{E}-07$ & $1,17 \mathrm{E}-06$ & $7,20 \mathrm{E}-06$ \\
\hline
\end{tabular}

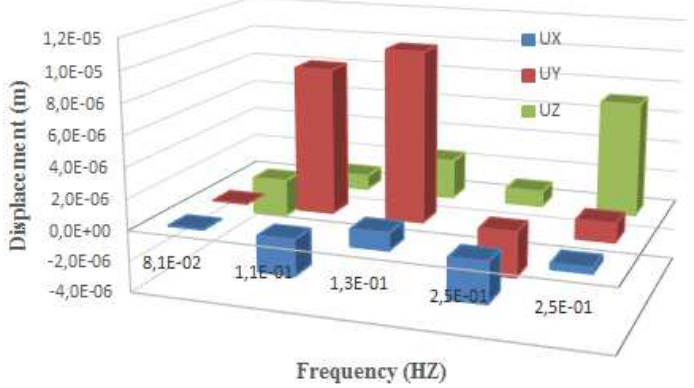

Fig. 3. Variation of displacements.

The interdependence of the mechanical behavior of the soil under the foundation and structure is called " soilstructure interaction." This phenomenon is greatly affected by the stiffness of the structure that depends on the construction materials, geometry and construction method.

The results of modal analysis show that the inclusion of soil-structure interaction is important in the analysis of the dynamic behavior of the dam because it has a remarkable influence in terms of increased natural periods of the structure and decreased displacements. This interaction is more or less important according to the nature of the soil, the characteristics of the structure and mode of foundation. It is in this context that the following section is based.

\subsubsection{Influence of foundation's depth}

We study the effect of foundation's depth on free vibration characteristics of the dam, we vary the depth as follows $\mathrm{h} 2>\mathrm{h} 1$. The results obtained are shown in figure 4. 


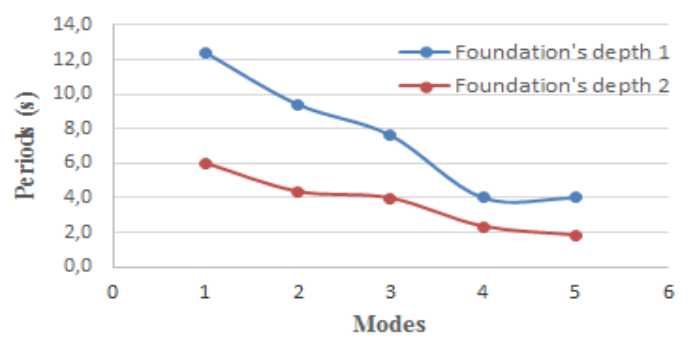

Fig. 4. Comparison of periods.

We have decreasing natural periods of the dam with the increasing depth of the foundation; the influence of the interaction appears significantly.

\subsection{Dynamic time history analysis}

Time history analysis is a part of structural analysis and is the calculation of the response of a structure to any earthquake. It is one of the main processes of structural design in regions where earthquakes are prevalent.

\subsubsection{Seismic record}

Al Hoceima region (northeast) experienced an earthquake on February 24, 2004, with a magnitude of 6.3 degrees on the Richter scale [9], causing human and material damage.

Morocco, located on a fracture zone, has already suffered deadly earthquakes. In this unstable region, earthquakes are caused by the rise of the African plate towards the European plate. The Atlas chains thus continue their overlap movements and from time to time the enormous accumulated tensions are released in the form of an earthquake

By exciting the dam by this earthquake (Figure 5), we observed its instantaneous responses. Node (N1933) at the dam crest is selected to represent the time history graphs of vertical movement at the dam crest.

The value of the damping ratio used in this study is $5 \%$. The effects caused by the earthquake such as acceleration, displacements and velocity are summarized in graphs that are discussed in the next paragraph.

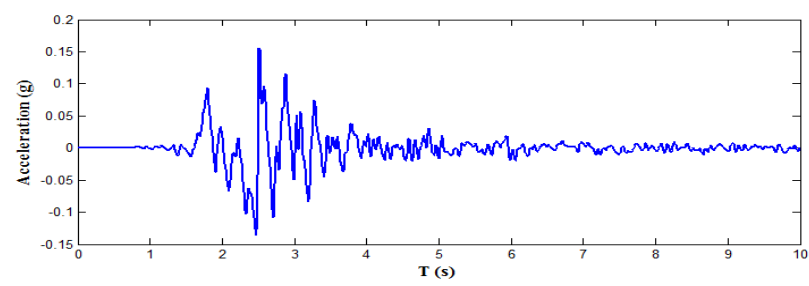

a) Acceleration.

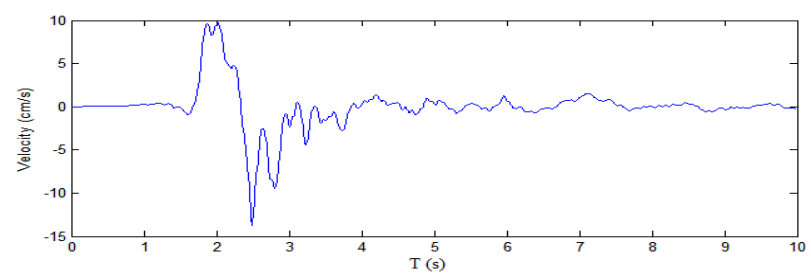

b) Velocity.

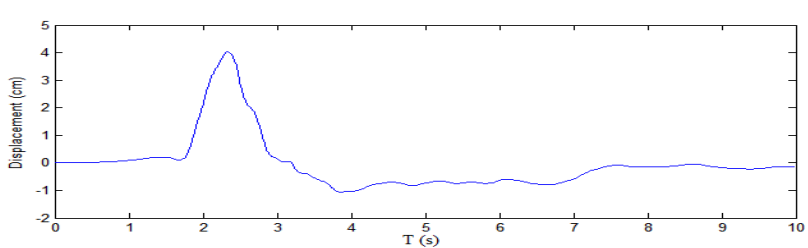

c) Displacement.

Fig. 5. AL HOCEIMA earthquake's record: Acceleration, velocity, displacement.

\subsubsection{Analysis results}

Figure 6 shows the variation of the acceleration and the velocity as a function of time for the node 1933 situated at the crest of the dam, and an acceleration amplification $(\operatorname{amax}=1.4 \mathrm{~g})$ is observed.

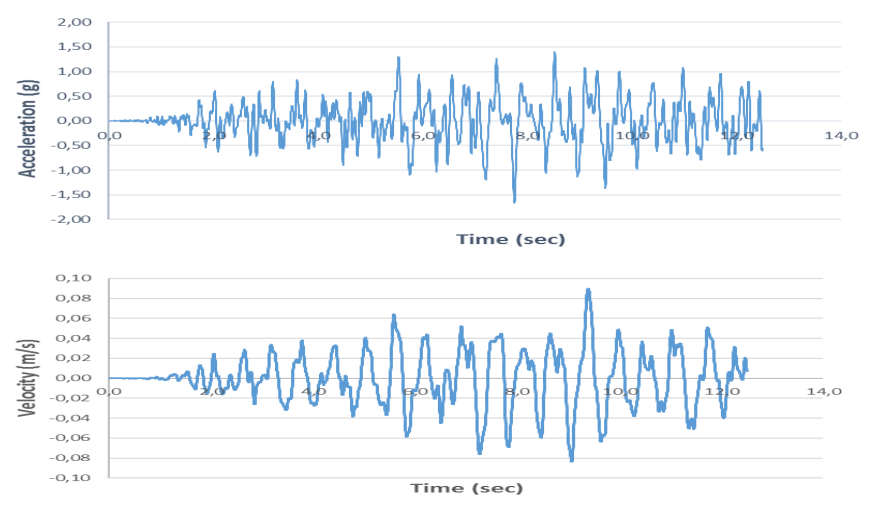

Fig. 6. Acceleration and velocity at the dam crest.

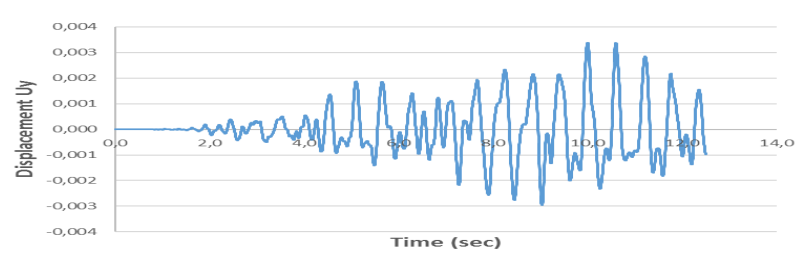

Fig. 7. Time history graphs of the vertical displacements.

Figure 7 show the time history graphs of the vertical displacements of the nodal point (1933) located at the crest of the dam with the considering of the interactions. The maximum value of displacement is $0,34 \mathrm{~cm}$.

The soil-structure interaction problem is solved for the embankment dam with a simplified, linear time history analysis, considering three models:

- Model 1: dam only, no foundation, no damping. Eq.1 reduces to :

$\mathrm{M}_{\text {structure }} \ddot{u}+\mathrm{K}_{\text {structure }} u=-\mathrm{M}_{\text {structure }} 1 \ddot{u}_{g}(t)$

- Model 2: dam only, no foundation, with damping. Eq. 1 reduces to :

$\mathrm{M}_{\text {structure }} \ddot{u}+\mathrm{C} \dot{u}+\mathrm{K}_{\text {structure }} u=-\mathrm{M}_{\text {structure }} 1 \ddot{u}_{g}(t)$

- Model 3: dam with foundation (with $\gamma_{\text {rock }}=\gamma_{\text {embankment }}$ $=23 \mathrm{kN} / \mathrm{m} 3$ ), with damping. Eq. 1 can be rewritten:

$\mathrm{M}_{\mathrm{ot}} \ddot{u}+\mathrm{C} \dot{u}+\mathrm{K}_{\mathrm{tot}} u=-\mathrm{M}_{\mathrm{tot}} 1 \ddot{u}_{\mathrm{g}}(t)$ 


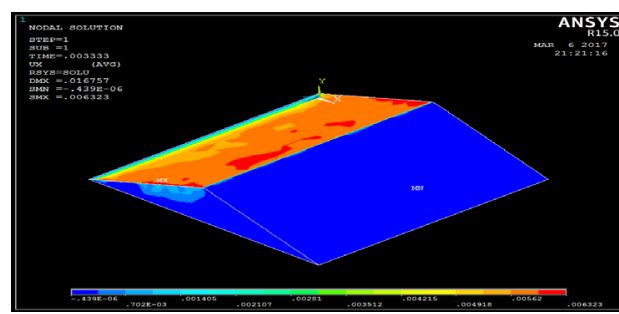

a) Model 1 .

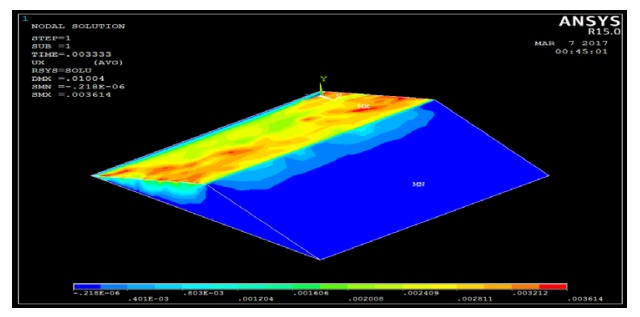

b) Model 2.

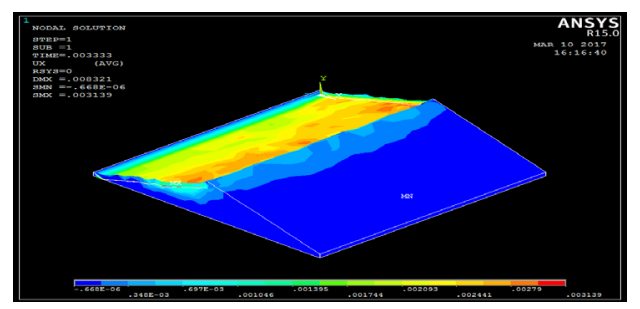

c) Model 3.

Fig. 8. The three considering models for introducing rigorously both the structure and the underlying rock foundation.

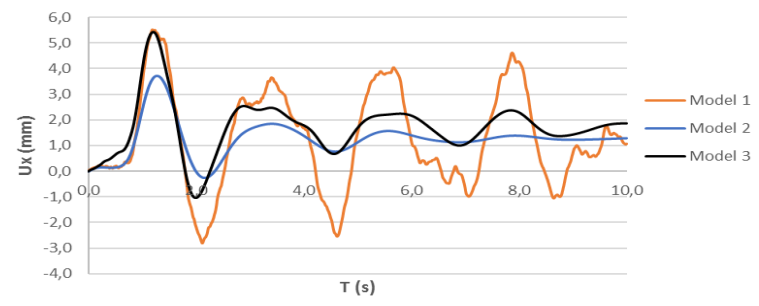

Fig. 9. Displacement time history of the node at the crest of dam.

The radial displacement time history Ux at dam's crest is illustrated in Figure 9. Model 2 (dam without foundation) gives a smaller maximal displacement with respect to Model 1, because of the introduction of the $5 \%$ damping.

A significant amplification of the signal can be noticed for Model 3 with respect to Model 2, which is due to the reflection of the waves on the classical boundary conditions. In order to limit this effect in the soil-structure interaction problem, one would have to extend the domain, or use transmitting boundaries, allowing the signal to leave the domain.

\section{Conclusion}

When a dam and its foundation are subjected to an earthquake, it generates an acceleration field which depends on the shape of the dam and the various constituent materials. Depending on the stiffness of materials and their internal damping capacity, depending on the height and shape of dam in relation to the earthquake spectrum, the response of dam will be more or less strong. This response is also influenced by the characteristics of the foundation and the restraint; Therefore, good consideration of soil-structure and fluidstructure interactions is essential. As in general terms, the characteristics of materials depend on the deformations to which they are subjected (non-linearities) and in particular, on shear deformations or distortions, it is generally necessary to study the response of the dam and its foundation to earthquake.

This paper studies the parametric finite element analysis of an embankment dam with ANSYS software and ANseismic programm. The aim of this work is to contribute to the study of the effects of soil-structurefluid interactions on the seismic response of civil engineering structures, and more specifically to embankment dams. Another aspect of the work involves a comparative study of numerical models; It has been shown in this paper that when the foundation is rigid enough, simplifying hypotheses allow the use of classical displacement boundary conditions to solve an approximate problem (Model 2 is applicable). Otherwise, in the presence of soft soils, the full soil-structure interaction problem should be solved with the help of transmitting boundaries.

\section{References}

1. Seghir, Contribution à la modélisation numérique de la réponse sismique des ouvrages avec interaction solstructure et interaction fluide-structure-Application à l'étude des barrages poids en béton, Université de Béjaia, Faculté de Technologie.

2. X. Zhang, Modélisation physique et numérique des interactions sol-structure sous sollicitations dynamiques transverses, Université de Grenoble (2011).

3. C. Liu, L. Zhang, B. Bai, J. Chen, J. Wang, Nonlinear analysis of stress and strain for a clay core rock-fill dam with FEM. Proc. Eng. 31 : 497-501, (2012).

4. M. Boumaïza, Contribution à l'étude et à l'analyse du comportement des barrages en terre et de leur stabilité, 76-77, (2010).

5. E. H. DILL, The Finite Element Method for Mechanics of Solids with ANSYS Applications, (2007).

6. M.A. Hariri-Ardebili, Y. Zarringhalam, H.E. Estekanchi, M. Yahyai, Nonlinear seismic assessment of steel moment frames using time-history, incremental dynamic, and endurance time analysis methods Sci. Iran. A (2013) 20 (3), 431-444.

7. K. J. Bathe and E. L. Wilson, Numerical methods in finite element analysis, Prentice-Hall, Englewood Cliffs, N. J., (1976), 528.

8. E. Javelaud, Revue Française de Géotechnique, Nearfield displacement and rotations estimated from strong-motion accelerometers, 146 (2016).

9. La réglementation parasismique au Maroc - RPS 2011, Royaume du Maroc, Ministère de l'Habitat, de l'Urbanisme et de l'Aménagement de l'Espace. 